Assessing variations in the expression of gratitude in youth: A three-cohort replication in southern Brazil

By: Lia B. L. Freitas, Elisa A. Merçon-Vargas, Fernanda Palhares, and Jonathan R. H. Tudge

Freitas, L. B. L., Merçon-Vargas, E. A., Palhares, F., \& Tudge, J. R. H. (2019). Assessing variations in the expression of gratitude in youth: A three-cohort replication in southern Brazil. Current Psychology. https://doi.org/10.1007/s12144-019-00334-6

This is a post-peer-review, pre-copyedit version of an article published in Current Psychology. The final authenticated version is available online at: http://dx.doi.org/10.1007/s12144-019-00334-6.

\begin{abstract}
***(C) 2019 Springer Science+Business Media, LLC, part of Springer Nature. Reprinted with permission. No further reproduction is authorized without written permission from Springer. This version of the document is not the version of record. ***
\end{abstract}

\begin{abstract}
:
Children are not born grateful; their understanding and expression of gratitude develops during childhood and adolescence. We used a qualitative measure designed to assess how youth would respond to a benefactor, hypothesizing that their types of responses would systematically alter with age, and were able to test the reliability of this measure via replication across three cohorts. Participants $(N=1101)$ aged 7 to 14 constituted three independent cohorts $(2008,2012$, and 2015-2017) from the same southern Brazilian city. Participants' responses were reliably coded into three types of gratitude (verbal, concrete, and connective); across samples, older youth were more likely to express verbal and connective gratitude; younger youth were more likely to express concrete gratitude. The age-related patterns of expression were very similar in each of the three samples (one discrepant result from nine possible), suggesting that it is a reliable measure with which to assess age-related changes in the expression of youth gratitude. Gratitude, we suggest, is not simply a unidimensional construct allowing judgments of how grateful individuals are; instead, our research suggests that youth of different ages express different types of gratitude, increasingly more complex, the most sophisticated of which comes closest to gratitude as a virtue.
\end{abstract}

Keywords: Adolescence | Cross-cultural | Moral development | Prosocial behavior

\title{
Article:
}

Children are not born grateful; their understanding and expression of gratitude develops during childhood and adolescence. This research examines age-related changes in the expression of gratitude in three samples of Brazilian youth. But what is gratitude, and how should it be measured? There are two related issues - conceptualization and measurement. Before attempting to measure the construct, one must be clear about what it is. As Roberts (2004) wrote about gratitude: "If we are to have a science of something, we had better have a pretty clear idea about what that thing is and be careful not to confuse it with other things that are a little bit like it" (p. 
65). This is difficult, however, when it is defined in several different ways or very broadly, whether treated as a trait (a disposition) or as a multifactorial construct (Lin 2017, 2018). For example, Emmons and Crumpler (2000) stated: "Gratitude has been conceptualized as an emotion, a virtue, a moral sentiment, a motive, a coping response, a skill, and an attitude. It is all of these and more" (p. 56). Similarly, Wood et al. (2010) noted that gratitude encompasses the following range of things: an appreciation of other people; appreciating what one has; "feelings of awe when encountering beauty;" behaviors that express gratitude; focusing on the positive; appreciating the fact that life is short; and making "positive social comparisons" (p. 891). For Watkins et al. (2004) "three aspects characterize dispositional gratitude: an appreciation for others, an appreciation for simple pleasures, and a sense of abundance" (p. 53).

The result is that conceptual confusion about the meaning of gratitude is rife (Carr 2013; Gulliford et al. 2013; Merçon-Vargas et al. 2018; Tudge and Freitas 2018). Fagley (2016) pointed out that one of the conceptual confusions is with appreciation, a much broader construct than gratitude. Appreciation involves understanding the "value and significance of somethingan event, a person, a behavior, an object - and feeling a positive emotional connection with it" (p. 71). She defined gratitude more narrowly, as "a positive emotional reaction directed to a benefactor for some perceived benefit he/she intentionally provided or attempted to provide" ( $p$. 73). Our view is that there is still something missing from the definition - the desire to reciprocate, if possible, to that benefactor. Individuals who typically feel this "positive emotional reaction" toward their benefactors but who rarely or never wish to reciprocate in any way are not considered grateful but ungrateful (Emmons 2016). There is evidence that from at least five years of age children disapprove of ungrateful people and, from eight years of age, the most common justification for a negative judgment about another person is the lack of reciprocity when the situation seems to require it (Freitas et al. 2011).

Our definition of gratitude thus consists of three interrelated parts. First, there should be a benefactor, one who freely and intentionally provides, or attempts to provide, some benefit to a beneficiary. Second, the beneficiary should recognize and feel good about the benefactor and his or her good intentions. Third, the beneficiary should freely wish to reciprocate to the benefactor, if possible and when appropriate, with something deemed to be of value to the benefactor (Tudge et al. 2015). This definition draws on writing about gratitude in philosophy (Carr 2013; ComteSponville 2002; Gulliford et al. 2013; Kristjánsson 2015; McConnell 1993; Smith 1759/2000), anthropology (Godbout, 1992; Komter 2004), biology (Bonnie and de Waal 2004), and psychology (Baumgarten-Tramer 1938; Piaget 1954/1981, 1965/1995). It fits very well with the concept of gratitude as a moral virtue.

As part of a moral virtue, this type of reciprocity is not that of a contract to be fulfilled. Card (1988) noted, writing about the difference between formal (contractual) and informal ties of obligation, such as those of friendship: "Contractual bonds are not the only ethically significant interpersonal ties" (p. 120). The type of obligation involved in virtue is one that comes from within rather than being imposed from outside - a morally virtuous individual genuinely and autonomously wishes to reciprocate to those who have helped; a formal contract is quite unnecessary. A similar distinction has been drawn between exchange and communal reciprocity (Clark and Mills 1993; Miller et al. 2014; Mills and Clark 1982) or between negotiated and reciprocal exchange (Molm et al. 2012) with the former treated as a contract to be negotiated and 
fulfilled and the latter arising from a community-wide or individual feeling that people should feel good about helping those who have helped them.

How do people attain such a moral virtue? No one is born grateful; gratitude, a socially, emotionally, morally, and cognitively complex phenomenon, is in the process of development during childhood and adolescence and continues developing during adulthood (Emmons and Shelton 2002). Early precursors may be the prosocial feelings, such as empathy and trying to help others, that are present in the first year or two of life (Carlo 2014; Killen and Smetana 2015). But the feeling and expression of gratitude also require a good deal of cognitive, socioemotional, and moral development (Tudge et al. 2015). An early prerequisite is theory of mind (Nelson et al. 2013), but knowing another person's intentions and understanding how best to respond in an appropriate way requires more than simply knowing that others see the world differently (Morgan and Gulliford 2018).

There is some evidence that parental gratitude (however assessed) has some links to their children's gratitude. Parents who are more grateful for their material possessions have children who are also more grateful for material things (Ramsey et al. 2018). Moreover, parents who say they are more grateful have children who say they feel more helped, and the extent to which they feel helped is related to their own expression of gratitude (O'Brien et al. 2018). It may be that parents who are more grateful themselves are more invested in encouraging gratitude in their children. They may do this in various ways.

For example, parents in many cultures work hard to get their young children to say "thank you" (or its equivalent) when receiving gifts or help (Visser 2009). They may also encourage their young children's empathy towards others and help them take other people's perspectives (Carlo 2014; Killen and Smetana 2015). As children become older, parents try different strategies to encourage gratitude in their children, particularly to be appreciative of the things they have, not to feel "entitled," and even to express gratitude as a "way of being" linked to a "practiced art or a way of life" (Halberstadt et al. 2016, p. 445). Interestingly, similar strategies are reported both from predominantly North American White and wealthy families (Halberstadt et al. 2016; Hussong et al. 2018a; Hussong et al. 2018b; Rothenberg et al. 2017) and from North American Black parents, from both middle- and working-class families (Leon 2018). These strategies include (a) parental modeling of gratitude, (b) talking to their children about situations in which the latter could have expressed gratitude, and (c) by putting them in situations in which they can both understand why they should be appreciative of what they have while at the same time have the opportunity to "pay forward" to those who have less.

However, children saying "thank you" because they have learned that it is the polite thing to do, or feeling grateful for (i.e., appreciative of) the material possessions they have is a long way from gratitude as a virtue. Even children reciprocating for help provided because they have been told they must do so is quite different from doing the same thing from a heartfelt desire to reciprocate (Mendonça and Palhares 2018). In part, parents realize that their cultivation of gratitude in their children is a long-term project (Hussong et al. 2018a). More than this, however, both parents' and children's understanding of what it means to be "grateful" seems far closer to appreciation as Fagley (2016) defined it. Whether parents are asked to describe what their children are grateful for (Halberstadt et al. 2016) or whether parents and children are asked about 
the things for which they are grateful (Ramsey et al. 2018) very few even mention gratitude to a benefactor for any specific benefit, let alone the idea that one should reciprocate to such a benefactor. Most common examples include being happy for material things, appreciating what one has, being thankful for participating in specific activities, and being grateful for specific people (e.g., parents or teachers) but for unspecified reasons (Ramsey et al. 2018).

There is, of course, no reason to expect parents or children to define their terms in the way that developmental scientists should, and in general parlance gratitude, appreciation, and thankfulness are treated as synonymous - measures using all three have alpha coefficients ranging from .78 in children to .94 in adults (Algoe and Stanton 2012; Froh et al. 2011). Our interest, however, is in gratitude as a virtue, and that is defined in a manner quite different from appreciation. Moreover, being developmentalists, we wish to know whether older youths' expressions of gratitude differ in important ways from those of their younger counterparts. Parents seem clear about the fact that as their children get older they should be more likely to express gratitude if they get the appropriate help and support (Hussong et al. 2018a, b; Leon 2018; O'Brien et al. 2018). Although Ramsey and her colleagues reported some variation with age in the type of things for which their 7- to 13-year-old children said they were grateful, none of the remaining sets of authors (Hussong et al. 2018a, b working with 6- to 9-year-olds; Leon 2018; O’Brien et al. 2018, each working with 7- to 14-year olds), examined changes with age in the expression of gratitude.

\section{Measuring Gratitude in Children and Adolescents}

As described above, one way in which scholars have sought to understand the development of youth gratitude is through interviews with the children themselves and with one or other of their parents (mostly mothers). Although this approach has the clear advantage of allowing participants to speak for themselves, it is problematic in that their use of words does not allow us to distinguish between gratitude and appreciation.

An alternative approach is quantitative, attempting to measure the extent to which youth feel trait gratitude. Most of these studies have relied on one or more of three scales (the Gratitude Questionnaire-6: GQ-6, McCullough et al. 2002; the Gratitude, Resentment, Appreciation Test: GRAT, Watkins et al. 2003; the Gratitude Adjective Checklist: GAC, McCullough et al. 2002). Although these scales are useful for assessing the extent to which youth say they are grateful, given our conceptualization of gratitude there are some serious limitations. First, few of the scales' items refer to human benefactors and none to the desire to reciprocate. Second, many of the items - including two of the three sub-scales of the GRAT - refer explicitly to appreciation and seem to fit far better with Fagley's (2016) definition of that concept than with gratitude per se. From our point of view, this means that they suffer from the same problem as do the interview studies. Third, although Froh and his colleagues (Froh et al. 2011) argued that each measure has reasonable psychometric properties for youth as young as age 10, each of the measures was designed to study variations in the extent to which adults feel grateful rather than the expression of types of gratitude, differing in complexity, that occur during childhood and adolescence. 
We have therefore adopted a different approach, one that relies on children's open-ended responses to a pair of questions, originally developed by Baumgarten-Tramer (1938). Her Swiss participants, aged 7 to 15, responded to two questions: "What is your greatest wish?" and "What would you do for the person who granted you this wish?" A benefactor is clearly implied, as is a positive emotion if one's greatest wish is fulfilled, and participants are questioned about how they would reciprocate (although some children respond with "nothing" or "don't know"), thus meeting all of our definition's requirements. A further advantage of this approach is that, unlike the scales previously described, this method was designed specifically for use with children and adolescents.

Baumgarten-Tramer (1938) found that youth typically responded to the second question with one of three types of responses, each of which incorporates some degree of reciprocity. In other words, she demonstrated that gratitude is not a unidimensional construct that lends itself to a simple assessment of being more or less grateful. The simplest is to reciprocate verballywhether a polite or a heartfelt response is not always apparent - and Baumgarten-Tramer termed it "verbal gratitude." A second type of gratitude is to show a desire to give something back, although what is offered has more to do with the beneficiary's needs or desires than with those of the benefactor (termed "concrete gratitude"). The most sophisticated type of gratitude requires considering what the benefactor might like or need and trying to provide it if at all possible ("connective gratitude"). Although both verbal and concrete gratitude are socially oriented, only connective gratitude takes the benefactor's wishes or needs into account. As such, it is more complex than either of the others, and comes closest to gratitude as a virtue.

Baumgarten-Tramer (1938) noted that between $30 \%$ and $48 \%$ of her 7 - to 14 -year-old participants expressed verbal gratitude, but that $72 \%$ of 15 -year-olds did so. She stated that concrete gratitude clearly declined with age whereas connective gratitude "becomes more frequent from the $11^{\text {th }}$ year and for the group aged 12 it occurs in $60 \%$ of all cases" $(1938$, p. 62). Subsequent replications with children and young adolescents in different parts of the world have provided some support for her overall findings, with similar age-related rates of decline or increase in the expression of each type of gratitude in some societies but not all (Mendonça et al. 2018; Payir et al. 2018; Wang et al. 2015).

This approach is different from those that are most commonly employed, whether qualitative interviews in which parents and children are asked about whether, and how, children are encouraged to express gratitude, or the quantitative measures that assess variations in the extent to which individuals say they feel grateful. By contrast, Baumgarten-Tramer's (1938) measure is qualitative and allows understanding of variations by age in the types of gratitude that youth express. The latter measure clearly fits well with our definition of gratitude and the close ties between conceptualization and operationalization are sufficient reason to use it.

The present study thus makes a unique contribution to our understanding of the development of gratitude in that it permits not only the investigation of age-related changes in the expression of types of gratitude that vary in complexity but also to examine whether these changes hold across different samples of children from the same Brazilian city. Any replication of findings strengthens our claim that the development of gratitude in youth is not linear but needs to be 
studied multidimensionally, taking into account the varied complexity of the different types of gratitude.

\section{Method}

Participants and Procedures

Three samples of children and adolescents aged 7 to 14 participated in separate studies about gratitude and materialism in a southern Brazilian city. Data were collected in 2008, 2012, and between 2015 and 2017. All participating children $\left(N=1101, M_{\text {age }}=10.58\right.$ years, $S D=2.11$; $56.9 \%$ girls; $63.9 \%$ from public schools) were recruited through their schools. Consent letters were sent home with children. Children whose parents consented and who also gave their own assent completed the measures at school. Full details of each sample are provided in Table 1.

Table 1. Descriptive information about each sample

\begin{tabular}{|lllll|}
\hline & Sample 1 & Sample 2 & Sample 3 & Overall \\
\hline Mean age $(S D)$ & $10.35(2.09)$ & $10.64(2.09)$ & $10.86(2.15)$ & $10.58(2.11)$ \\
Gender & $57.9 \%$ girls & $58.2 \%$ girls & $53.7 \%$ girls & $56.9 \%$ girls \\
School type & $62.1 \%$ public & $60.3 \%$ public & $71.4 \%$ public & $63.9 \%$ public \\
Gratitude & & & & \\
$\quad$ Verbal & $217(50.47 \%)$ & $171(44.07 \%)$ & $130(45.94 \%)$ & $518(47.05 \%)$ \\
Concrete & $118(27.44 \%)$ & $119(30.67 \%)$ & $72(25.44 \%)$ & $309(28.07 \%)$ \\
Connective & $178(41.40 \%)$ & $116(29.90 \%)$ & $102(36.04 \%)$ & $396(35.97 \%)$ \\
$N$ & 430 & 388 & 283 & 1101 \\
\hline
\end{tabular}

Although the first author planned and guided each of the three studies, data were collected and coded by different individuals in each study. As the methods in each study were the same, we were able to use the three sets of data to assess replicability. Participants were drawn from a total of six public schools, two of which contributed participants to both the first and third samples and one of which provided data to the second and third samples, and from a total of seven private schools, one of which contributed participants to both the first and second samples.

Measures

Gratitude. Participants responded to the first two questions (i.e., those used by BaumgartenTramer 1938: "What is your greatest wish?" and "What would you do for the person who granted you that wish?") from the Wishes and Gratitude Survey (WAGS: Freitas et al. 2008, adapted from Baumgarten-Tramer 1938). Here we are only reporting responses to the second question. These responses were coded as 1 (expressed) or 0 (not expressed) in the following gratitude categories: verbal gratitude, concrete gratitude, and connective gratitude. Verbal gratitude, as the name suggests, includes the various ways in which people can express gratitude verbally, from a simple "I would thank him" to "I would thank her from the very bottom of my heart." Concrete gratitude involves the desire to give something to the benefactor, such as: "I would give them 5000 pieces of candy," or "Give them a trampoline." The expressed intention is to reciprocate, but with things that the beneficiary, rather than the benefactor, might like or appreciate. Connective gratitude takes the benefactor's wishes or needs into account. As one child said, "Help them if they needed help," and another one, whose wish was to become a 
doctor, responded "I would not let them pay whenever they got hurt and had to go to the hospital, them or their family." Other responses included "don't know," "uncodable" (when we could not understand what the child had written), "finalistic" (stating, for example, that one would repay by becoming the best possible footballer if granted the wish to play for the team of her dreams), or "self-sufficient" (when the child felt that his or her wish could only be attained by his or her own efforts), but these were rare responses and will not be considered further in this paper. At least $25 \%$ of the responses to both questions were coded by two members of the research group (kappa .70 to .98). All disagreements were discussed and resolved. Hypotheses

Our primary hypothesis was that the pattern of expression of gratitude, by children's age, would be the same across the three samples. Specifically, we hypothesized that, consistently across samples, older children would be more likely to express verbal and connective gratitude than would those who were younger, whereas the latter would be more likely to express concrete gratitude. That is, we do not expect samples to moderate the associations between age and gratitude types.

\section{Results}

\section{Preliminary Analyses}

Descriptive statistics of all principal variables are shown in Table 1, including frequencies of types of gratitude. When children provided more than one answer to the gratitude question, each type of gratitude was coded as expressed (some descriptive statistics in Table 1 therefore exceed $100 \%$ ). A one-way ANOVA indicated that the mean age differed significantly across samples $\left(F[2,1098]=5.08, p=.006, \eta^{2}=.009\right)$, although the effect size was minimal; Bonferroni posthoc tests showed that children in sample three $\left(M_{a g e}=10.86, S D=2.15\right)$ were, on average, older than were children in the first sample $\left(M_{\text {age }}=10.35, S D=2.09\right)$. Logistic regression revealed that children in the third sample were about 1.5 and 1.6 times more likely to come from public schools than were children in the first $\left(e^{B}=1.52, p=.011\right)$ and second samples $\left(e^{B}=1.64, p=.003\right)$ respectively, and so "school type" was retained as a control variable. Gender was also retained as a control variable because males were about 1.4 times less likely to express verbal gratitude than were females $\left(e^{B}=.719, p=.009\right)$.

Our primary interest was whether the patterns of age-related expressions of different types of gratitude were found in each of the three samples, controlling for the variation across samples both in the average age of each sample and in the proportion of children from public and private schools. We therefore ran a series of logistic regression analyses, the independent variables being Age (as a continuous variable), Sample (1, 2, 3), School Type (public vs. private), Gender, and the interaction of Sample by Age. Each analysis had Verbal, Concrete, or Connective Gratitude as the dependent variable $(0=$ not expressed; $1=$ expressed $)$. Each analysis was run twice, first with Sample 3 as the reference category (to assess differences between it and Samples 1 and 2) and then with Sample 1 as the reference category (to assess whether it differed from Sample 2). Finally, separate logistic regression analyses were run for each sample, independent variables being Age (in years), School Type (public vs. private), and Gender, with each type of gratitude as the dependent variable $(0=$ not expressed; $1=$ expressed $)$. 
The Expression of Gratitude Across Samples

Verbal Gratitude. Examining the interaction of age and samples (see Fig. 1) revealed that Sample 3 did not differ significantly from either Sample 1 or Sample 2, and Sample 1 did not differ significantly from Sample 2 (as shown in Tables 2 and 3). These results revealed that, as hypothesized, for every year's increase in age youth were more likely to express verbal gratitude $\left(B=.183, e^{B}=1.20, p<.001\right.$ for Sample $1, B=.279, e^{B}=1.32, p<.001$ for Sample 2, and $B=.174, e^{B}=1.19, p=.004$ for Sample 3).

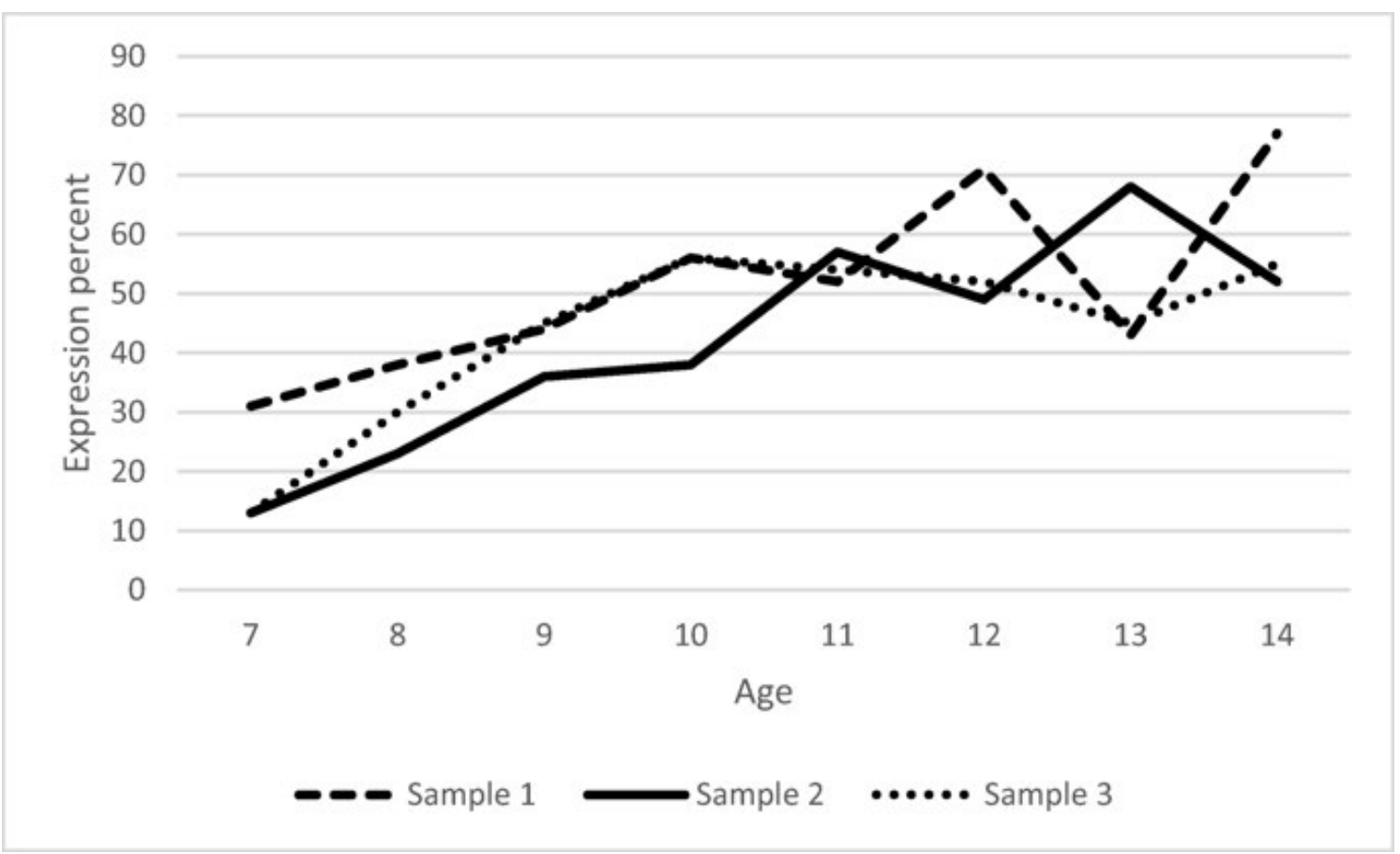

Figure 1. The expression of verbal gratitude, by age, across the three samples

Table 2. Logistic regression analyses of types of gratitude on age, gender, and samples (with sample 3 as reference group)

\begin{tabular}{|c|c|c|c|c|c|c|c|c|c|}
\hline \multirow[b]{3}{*}{ Predictor } & \multicolumn{9}{|c|}{ Gratitude types } \\
\hline & \multicolumn{3}{|c|}{ Verbal } & \multicolumn{3}{|c|}{ Concrete } & \multicolumn{3}{|c|}{ Connective } \\
\hline & $B$ & $S E B$ & $e^{B}$ & $\bar{B}$ & $S E B$ & $e^{B}$ & $\bar{B}$ & $S E B$ & $e^{B}$ \\
\hline Age & $.18^{* *}$ & .06 & 1.19 & $-.24 * * *$ & .07 & .78 & .10 & .06 & 1.10 \\
\hline Sample 3 vs. 1 & .15 & .82 & 1.16 & 1.56 & .91 & 4.75 & -.57 & .83 & .57 \\
\hline Sample 3 vs. 2 & -1.09 & .87 & .34 & -.29 & .90 & .75 & .59 & .88 & 1.79 \\
\hline School type & -.08 & .13 & .93 & $.33^{*}$ & .15 & 1.39 & $-.42 * *$ & .14 & .65 \\
\hline Gender & $-.32 * *$ & .13 & .72 & -.02 & .14 & .98 & -.02 & .13 & .98 \\
\hline Sample $1 \mathrm{x}$ age & .01 & .08 & 1.01 & -.16 & .09 & .85 & .08 & .08 & 1.08 \\
\hline Sample $2 \mathrm{x}$ age & .10 & .08 & 1.10 & .05 & .09 & 1.05 & -.08 & .08 & .92 \\
\hline Nagelkerke $R^{2}$ & .08 & & & .10 & & & .04 & & \\
\hline$\chi^{2}$ & $64.48 * * *$ & & & $79.14^{* * *}$ & & & $33.87 * * *$ & & \\
\hline
\end{tabular}

$e^{B}=$ exponentiated $B$ (beta). Gender coded Male $=0$, Female $=1$ (reference), School type coded Public $=1$,

Private $=2$ (reference). The Sample $\mathrm{x}$ Age interaction is in comparison to the Sample reference group

$* p<.05, * * p<.01, * * * p<.001$ 
Table 3. Logistic regression analyses of types of gratitude on age, gender, and samples (with sample 1 as reference group)

\begin{tabular}{|c|c|c|c|c|c|c|c|c|c|}
\hline \multirow[b]{3}{*}{ Predictor } & \multicolumn{9}{|c|}{ Gratitude types } \\
\hline & \multicolumn{3}{|c|}{ Verbal } & \multicolumn{3}{|c|}{ Concrete } & \multicolumn{3}{|c|}{ Connective } \\
\hline & $B$ & $S E B$ & $e^{B}$ & $B$ & $S E B$ & $e^{B}$ & $B$ & $S E B$ & $e^{B}$ \\
\hline Age & $.19 * * *$ & .05 & 1.21 & $-.40 * * *$ & .06 & .67 & $.17 * * *$ & .05 & 1.19 \\
\hline Sample 1 vs. 2 & -1.24 & .77 & .29 & $-1.85^{*}$ & .83 & .16 & 1.16 & .78 & 3.18 \\
\hline Sample 1 vs. 3 & -.15 & .82 & .86 & -1.56 & .91 & .21 & .57 & .83 & 1.77 \\
\hline School type & -.08 & .13 & .93 & $.33 *$ & .15 & 1.39 & $-.42 * *$ & .14 & .65 \\
\hline Gender & $-.32 * *$ & .13 & .72 & -.02 & .14 & .98 & -.02 & .13 & .98 \\
\hline Sample $2 \mathrm{x}$ age & .08 & .07 & 1.09 & $.21 * *$ & .08 & 1.23 & $-.16^{*}$ & .07 & .85 \\
\hline Sample $3 x$ age & -.01 & .08 & .99 & .16 & .09 & 1.17 & -.08 & .08 & .93 \\
\hline Nagelkerke $R^{2}$ & .076 & & & .10 & & & .04 & & \\
\hline$\chi^{2}$ & $64.48 * * *$ & & & $79.14 * * *$ & & & $33.87 * * *$ & & \\
\hline
\end{tabular}

$e^{B}=\operatorname{exponentiated} B$ (beta). Gender coded Male $=0$, Female $=1$ (reference), School type coded Public $=1$,

Private $=2$ (reference). The Sample $\mathrm{x}$ Age interaction is in comparison to the Sample reference group $* p<.05, * * p<.01, * * * p<.001$

Concrete Gratitude. Examining the interaction of age and samples (see Fig. 2) revealed that Sample 3 did not differ significantly from either Sample 1 or Sample 2 (see Tables 2 and 3 ). However, the rate of decline, with age, in the expression of concrete gratitude among the youth in Sample 1 was significantly steeper than was the case with their counterparts in Sample 2. The data revealed that youth in each sample significantly declined in their expression of concrete gratitude with each additional year of age $\left(B=-.397, e^{B}=.672, p<.001\right.$ in Sample $1, B=-.199, e^{B}=.819, p<.001$ in Sample 2, and $B=-.229, e^{B}=.795, p=.001$ in Sample 3 .

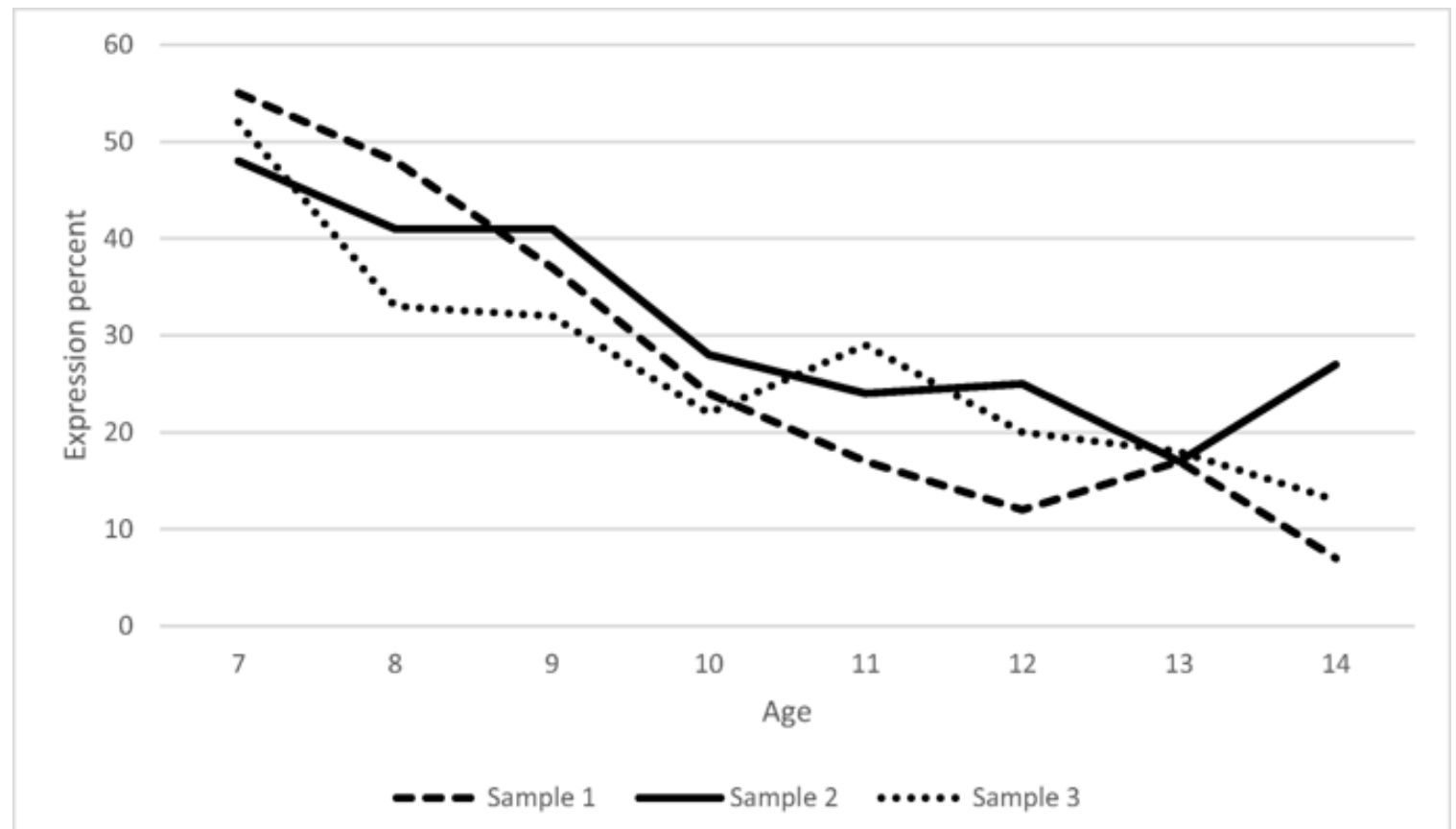

Figure 2. The expression of concrete gratitude, by age, across the three samples 
Connective Gratitude. The patterns of interaction between age and samples were not so clear in the case of connective gratitude (see Fig. 3) in that the youth in Sample 1 significantly increased their expression of connective gratitude, with age, whereas those in the other two samples did not. As shown in Tables 2 and 3, compared to youth in Sample 3, those in Samples 1 and 2 did not differ significantly. However, youth in Sample 1 differed significantly from those in Sample 2. With each increased year of age, youth in Sample 1 were 1.17 times more likely than those in Sample 2 to express connective gratitude. This was reflected in the separate analyses; youth in Sample 1 were the only ones to significantly increase their expression of connective gratitude with age $\left(B=.188, e^{B}=1.21, p<.001\right)$. However, neither in Sample 2 nor Sample 3 did we find a significant change with age in the expression of connective gratitude $(B=.003, n s$, in Sample $2 ; B=.103, n s$, in Sample 3).

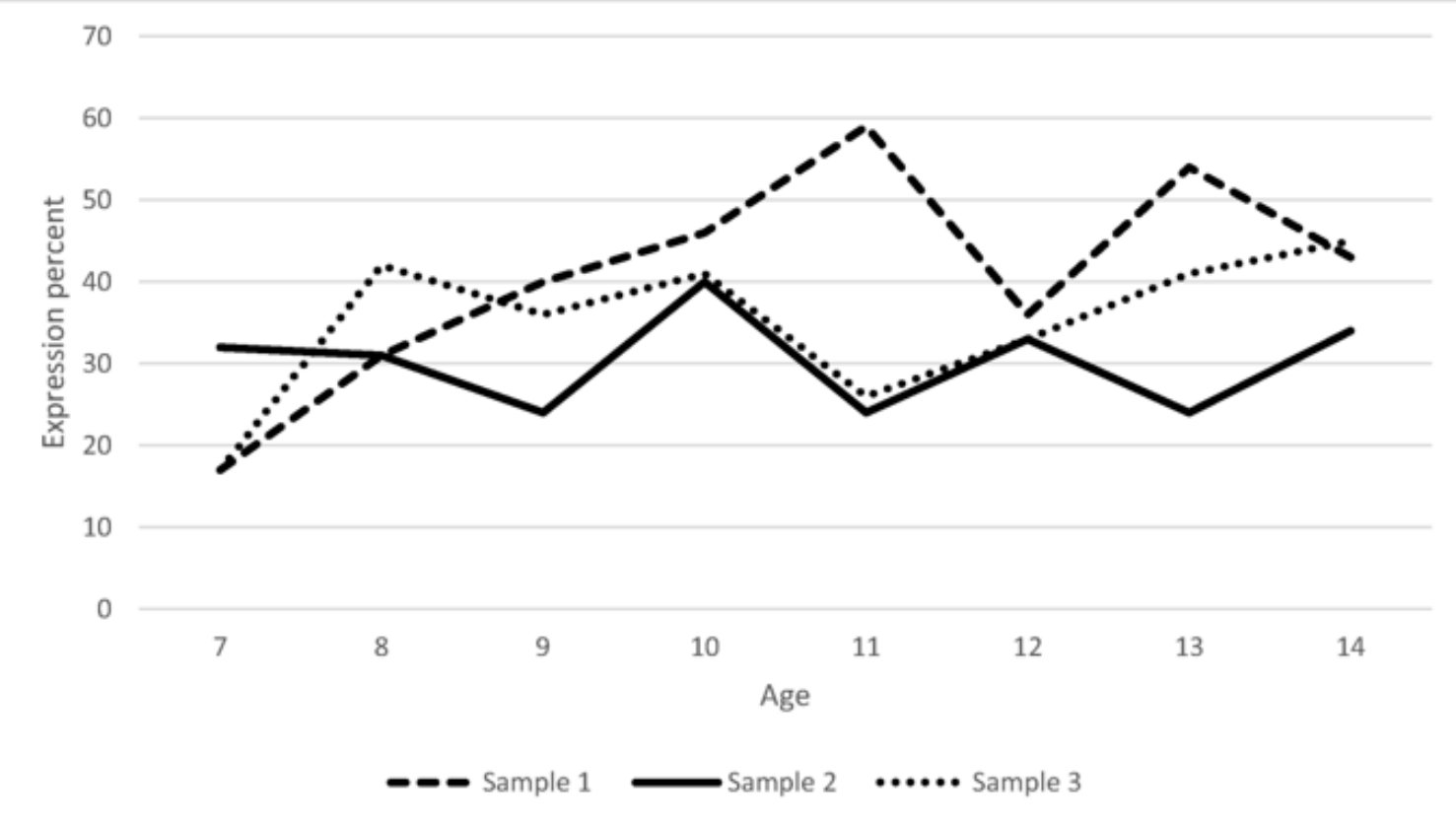

Figure 3. The expression of connective gratitude, by age, across the three samples

\section{Discussion}

The goal of this research was to evaluate variations by age in the type of gratitude expressed by children and young adolescents as well as to assess whether the same patterns of expression would be found in three different cohorts of same-age youth drawn from the same Brazilian city. By asking youth what they would do for someone who granted their greatest wish, the measure allows evaluation of whether - and if so, how - youth say they would reciprocate to their benefactor. It thus fits well with the way in which we think gratitude should be conceptualized. Reciprocity to a benefactor who provides a significant benefit may take the simplest form (a verbal acknowledgement), involve something that only the initial beneficiary is likely to appreciate (concrete gratitude), or something that takes the benefactor's wishes or needs into account (connective gratitude).

The measure used here has been used to assess the expression of gratitude in different societies, providing evidence of considerable cross-cultural variability in the expression of the expression 
of gratitude (Mendonça et al. 2018; Payir et al. 2018; Wang et al. 2015). However, it is difficult to know whether this cross-societal variability in findings is due to cultural factors that influence the ways in which children are encouraged to express gratitude or whether the measure is unreliable. If the measure is reliable, then replications in the same city, using three different samples of same-age participants, should yield very similar results.

In essence, this is what we found. Initially, the fact that the participants' responses could be reliably coded into one of three different types of gratitude should not be overlooked. Scales that measure how grateful (or appreciative) people say they are treat any type of appreciation as equivalent -no distinction is drawn between individuals who are often in awe at the natural world, those who are happy to say "thank you" to benefactors on a consistent basis (but do nothing more), and those who endeavor to reciprocate appropriately to their benefactors. There are important distinctions among the types of gratitude that youth express to their benefactors, and we should be wary of measures that treat gratitude as unidimensional.

Of most importance, however, was the extent to which the age-related patterns of the expression of gratitude were matched across the three samples. Overwhelmingly, they were. Of the nine possible outcomes (three gratitude types vs. three samples) eight were essentially the same. That is, the age-related differences in the expression of verbal gratitude were matched in each of the samples, with a significant increase with age in each of the three samples. Similarly, in each of the three samples the expression of concrete gratitude significantly declined with age (although in one sample the rate of decline was greater than in the other two). In the case of connective gratitude, and contrary to what we had hypothesized, in two of the samples there was no significant increase in the expression of connective gratitude with age. The sole discrepant result was that in one of the three samples there was a significant increase. These age-related changes are not simply that they expressed greater or lesser gratitude - as hypothesized, the changes are in the type of gratitude expressed.

We need to study further reasons for the fact that the most sophisticated type of gratitude expression, taking the benefactor's wishes and needs into account, was only found to increase significantly in one sample. That this was the only discrepant finding across the three samples does provide relatively strong support for our position that the use of different types of gratitude develops with age. At this point we can only speculate as to the reason why older children in two of the samples were not more likely to express connective gratitude, given that our other crosscultural studies had consistently shown such a finding (Mendonça et al. 2018; Payir et al. 2018; Wang et al. 2015). However, as with all such constructs, gratitude expression is not simply a personal characteristic but is influenced by the local, as well as cultural, context. Although we did not collect data on this, it would have been very interesting to have examined the classroom contexts of the 11- and 13-year-olds in Sample 2 and of the 11-year-olds in Sample 3, given the fact that those children were much less likely to express connective gratitude than expected.

Because four of the schools (three public and one private) were involved in two of the samples it is possible that some of the same children participated in two samples. However, given the fact that four years elapsed between the data collection of Samples 1 and 2 and a further three to five years prior to data collection using Sample 3 this should not be a major concern. Given the age- 
related variation in gratitude expression, any children who were involved in two samples would be most likely to express a different type of gratitude the second time.

\section{Conclusion}

Gratitude has received a good deal of scholarly attention, particularly since the turn of the century. In keeping with Roberts's (2004) position, we believe that it is important to define our constructs clearly, and then to operationalize them appropriately in a way that fits the definition. For this reason, we were unable to use any of the three most widely used scales, given that most of their items do not refer to a human benefactor, and none of them require any consideration of reciprocation to a benefactor. The willingness to reciprocate, however, is a key component of our definition of gratitude; without such willingness, beneficiaries are not grateful-they are ungrateful. We thus consider that these scales are in fact measures of appreciation, a far broader construct.

We do not mean that any type of reciprocity signifies gratitude; more is needed than a contractual exchange or reciprocating because an authority figure demanded it. Gratitude, as a moral virtue, means freely and willingly taking on an obligation to reciprocate if a suitable opportunity is available. Gratitude also involves more than just its expression - grateful individuals actually reciprocate to their benefactors when they have an opportunity to do so; the behavioral aspect is critical to gratitude. Simply saying that one would reciprocate but never actually doing so is a marker of ingratitude rather than of gratitude. However, it seems unlikely that the behavioral manifestation would develop in the absence of the verbal recognition of the fact that one ought to reciprocate. Even then, of course, to know whether individuals were acting on the basis of moral virtue one would have to assess whether the reciprocity was coming from within, autonomously, as opposed to involving some type of contract or heteronomous requirement.

In this study we only examined the expression of gratitude rather than its behavioral manifestation, and it may be the case that its expression simply reflects a socially derived sense of obligation to say the right thing. Given the extent to which parents in many parts of the world try hard to get their children to say "thank you" for gifts or help received (Visser 2009), the expression of verbal gratitude could well represent this type of polite response. The expression of connective gratitude, however, seems unlikely to fit into this category, given that it requires considering what the benefactor might like or need. Nonetheless, some type of lab-based study (as in, for example, Vaish et al. 2018) might be helpful to show the extent to which expression is matched with action. Even then, however, one would probably need to interview children following their behavioral manifestations of gratitude to ascertain whether those actions were being done autonomously.

We now have compelling evidence that there are age-related variations in the expression of different types of gratitude across childhood and early adolescence. The evidence derives both from cross-cultural findings (Mendonça et al. 2018; Payir et al. 2018; Wang et al. 2015) and from the replication of results from three cohorts from the same culture, presented in this paper. We thus should be wary about accepting results that simply show that youth vary in the extent to which they report they are grateful. It could mean that they feel that they consistently say "thank 
you" for presents and help received - perhaps simply an indication that they have learned to become polite. It could mean that they feel something about the benefactors who have helped them and wish to do something back for them if they have an opportunity — which we think comes closest to being virtuously grateful. It could also mean that they are appreciative for the nice house they live in and the fact that their families have the wealth to support them in the lifestyle to which they have become accustomed. These are all quite different ways of expressing what is too loosely called "gratitude." The Wishes and Gratitude Survey (WAGS: Freitas et al. 2008) seems to be an effective means of assessing variations in the type of gratitude youth express.

We do not wish to imply that the WAGS is the only possible means to assess gratitude as defined; as Tudge et al. (2015) noted there are other methods, such as the use of gratitude vignettes (Freitas 2007; Lin 2017; Morgan and Gulliford 2018)]. However, the WAGS does have the benefit of clearly fitting the definition, allowing us to distinguish gratitude from appreciation, is a simple measure to use and, as we have shown here, is reliable. Finally, it is not a difficult measure to translate into other languages and, because it is a qualitative measure with openended responses, it is culturally sensitive.

Although it is clear that there are age-related variations in the expression of these different types of gratitude, longitudinal research is required to assess the conditions under which children move from the expression of one type of gratitude to another. The process of expressing gratitude may begin long before children understand the term, when parents try to persuade children to say "thank you" when given a gift. It may be fostered particularly by parents who themselves are grateful and perhaps be linked to their encouragement of their children's empathy and ability to take others' perspectives (Carlo 2014; Killen and Smetana 2015). Interviews with a wide range of parents, from different countries, may well help us understand the conditions under which older children and adolescents are helped to become virtuously grateful, although the interviews might need to be more focused on gratitude to benefactors, and possible reciprocity, than has so far been the case (Halberstadt et al. 2016; Hussong et al. 2018a, b; Rothenberg et al. 2018).

Having a theory of mind and empathically taking others' perspectives in early childhood is likely to build or strengthen connections with others. These connections might encourage, during middle childhood and early adolescence, the development of connective gratitude, without which it seems unlikely that gratitude as a virtue could develop. This is an area in which empirical evidence is clearly needed. The goals of this paper, however, were to assess the extent to which there are age-related variations in the type of gratitude expressed by youth and to evaluate, via replication, the reliability of a measure designed for that purpose. Those goals, we think, have been attained.

Grant Support. Lia Freitas, Conselho Nacional de Desenvolvimento Científico e Tecnológico (CNPq), \#302688/2015-3 and 301714/2012-6, Coordenação de Aperfeiçoamento de Pessoal de Nível Superior (CAPES), BEX 2038/09-9; Elisa Merçon-Vargas, Coordenação de Aperfeiçoamento de Pessoal de Nível Superior (CAPES) BEX 0959/12-0; Fernanda Palhares, Coordenação de Aperfeiçoamento de Pessoal de Nível Superior (CAPES), \#001; Jonathan Tudge, The John Templeton Foundation, \#43510. 
Conflict of Interest. On behalf of all authors, the corresponding author states that there is no conflict of interest.

Ethical Approval. The datasets generated during and/or analyzed during the current study are available from the corresponding author on reasonable request. Each study was approved by the appropriate ethics committee of Universidade Federal do Rio Grande do Sul, and informed consent was appropriately gained from all participants in full compliance with ethical standards.

\section{References}

Algoe, S. B., \& Stanton, A. L. (2012). Gratitude when it is needed most: Social functions of gratitude in women with metastatic breast cancer. Emotion, 12, 163168. https://doi.org/10.1037/a0024024.

Baumgarten-Tramer, F. (1938). "Gratefulness" in children and young people. Journal of Genetic Psychology, 53, 53-66.

Bonnie, K. E., \& de Waal, F. B. M. (2004). Primate social reciprocity and the origin of gratitude. In R. A. Emmons \& M. E. McCullough (Eds.), The psychology of gratitude (pp. 213229). New York: Oxford University Press.

Card, C. (1988). Gratitude and obligation. American Philosophical Quarterly, 25(2), 115-127.

Carlo, G. (2014). The development and correlates of prosocial moral behaviors. In M. Killen \& J. G. Smetana (Eds.), Handbook of moral development ( $2^{\text {nd }}$ Ed., pp. 208-234). New York: Psychology Press.

Carr, D. (2013). Varieties of gratitude. The Journal of Value Inquiry, 47(1-2), 1728. https://doi.org/10.1007/s10790-013-9364-2.

Clark, M. S., \& Mills, J. R. (1993). The difference between communal and exchange relationships: What it is and is not. Personality and Social Psychology Bulletin, 19(6), 684-691.

Comte-Sponville, A. (2002). A small treatise on the great virtues: The uses of philosophy in everyday life. New York: Holt and Company (First published in French in 1996).

Emmons, R. A. (2016). Is gratitude queen of the virtues and ingratitude king of the vices? In D. Carr (Ed.), Perspectives on gratitude: An interdisciplinary approach (pp. 141-153). New York: Routledge.

Emmons, R. A., \& Crumpler, C. A. (2000). Gratitude as a human strength: Appraising the evidence. Journal of Social and Clinical Psychology, 19, 5669. https://doi.org/10.1521/jscp.2000.19.1.56.

Emmons, R. A., \& Shelton, C. M. (2002). Gratitude and the science of positive psychology. In C. R. Snyder \& S. J. Lopez (Eds.), Handbook of positive psychology (pp. 459-471). London: Oxford University Press. 
Fagley, N. S. (2016). The construct of appreciation: It is so much more than gratitude. In D. Carr (Ed.), Perspectives on gratitude: An interdisciplinary approach (pp. 70-84). New York: Routledge.

Freitas, L. B. L. (2007). Vignettes for the study of gratitude and moral obligation. Unpublished measure, Porto Alegre, Brazil.

Freitas, L. B. L., Tudge, J. R. H., \& McConnell, T. (2008). The wishes and gratitude survey. Greensboro: Unpublished questionnaire. (Adapted and expanded from Baumgarten-Tramer, 1938).

Freitas, L. B. L., Mileski, A. Z., \& Tudge, J. R. H. (2011). O juízo moral das crianças sobre a ingratidão [The moral judgment of children about ingratitude]. Aletheia, 34(1), 6-18.

Froh, J. J., Fan, J., Emmons, R. A., Bono, G., Huebner, E. S., \& Watkins, P. (2011). Measuring gratitude in youth: Assessing the psychometric properties of adult gratitude scales in children and adolescents. Psychological Assessment, 23, 311324. https://doi.org/10.1037/a0021590.

Godbout, J. T. (1992). L'esprit du don [The world of the gift]. Paris: La Découbert.

Gulliford, L., Morgan, B., \& Kristjánsson, K. (2013). Recent work on the concept of gratitude in philosophy and psychology. Journal of Value Inquiry, 47, 285317. https://doi.org/10.1007/s10790-013-9387-8

Halberstadt, A. G., Langley, H. A., Hussong, A. M., Coffman, J. L., Rothenberg, W. A., Mokrova, I, \& Costanzo, P. R. (2016). Parents' understanding of gratitude in young children: A thematic analysis. Early Childhood Research Quarterly, 26, 439-451. doi: https://doi.org/10.1016/j.ecresq.2016.01.014

Hussong, A., M., Langley, H. A., Coffman, J. L., Halberstadt, A. G., \& Costanzo, P. R. (2018a). Parent socialization of children's gratitude. In J. R. H. Tudge \& L. B. L. Freitas (Eds.), Developing gratitude in children and adolescents (pp. 199-219). Cambridge: Cambridge University Press.

Hussong, A. M., Langley, H. A., Rothenberg, W. A., Coffman, J. L., Halberstadt, A. G., Costanzo, P. R., \& Mokrova, I. (2018b). Raising grateful children one day at a time. Applied Developmental Science. https://doi.org/10.1080/10888691.2018.1441713.

Killen, M., \& Smetana, J. G. (2015). Origins and development of morality. In M. Lamb (Ed.), Handbook of child psychology, Vol. 3, Social and emotional development (pp. 701749). (7th Ed., R. M. Lerner, Series Ed.). New York: Wiley/Blackwell Publishers.

Komter, A. E. (2004). Gratitude and gift exchange. In R. A. Emmons \& M. E. McCullough (Eds.), The psychology of gratitude (pp. 195-213). New York: Oxford University Press.

Kristjánsson, K. (2015). An Aristotelian virtue of gratitude. Topoi, 34, 499511. https://doi.org/10.1007/s11245-013-9213-8.

Leon, E. D. (2018). Black parents' values for their children and their perceptions of their children's gratitude. Unpublished master's thesis, The University of North Carolina at Greensboro. 
Lin, C.-C. (2017). The effect of higher-order gratitude on mental well-being: Beyond personality and unifactorial gratitude. Current Psychology, 36, 127135. https://doi.org/10.1007/s12144-015-9392-0.

Lin, C.-C. (2018, in press). Perceived goodness mediates the relationship between trait and state gratitude. Current Psychology. https://doi.org/10.1007/S12144-018-0076-4.

McConnell, T. (1993). Gratitude. Philadelphia: Temple University Press.

McCullough, M. E., Emmons, R. A., \& Tsang, J. (2002). The grateful disposition: A conceptual and empirical topography. Journal of Personality and Social Psychology, 82, 112127. https://doi.org/10.1037//0022-3514.82.1.112.

Mendonça, S. E., \& Palhares, F. (2018). Gratitude and moral obligation). In J. R. H. Tudge \& L. B. L. Freitas (Eds.), Developing gratitude in children and adolescents (pp. 89-110). Cambridge: Cambridge University Press.

Mendonça, S. E., Merçon-Vargas, E. A., Payir, A., \& Tudge, J. R. H. (2018). The development of gratitude in seven societies: Cross-cultural highlights. Cross-Cultural Research, 52, 135-150. https://doi.org/10.1177/10693117737245.

Merçon-Vargas, E. A., Poelker, K. E., \& Tudge, J. R. H. (2018). The development of the virtue of gratitude: Theoretical foundations and cross-cultural issues. Cross-Cultural Research, 52, 3-18. https://doi.org/10.1177/10693117736157.

Miller, J. G., Bland, C., Källberg-Shroff, M., Tseng, Y.-C., Montes-George, K., Ryan, K., Das, R., \& Chakravarthy, S. (2014). Culture and the role of exchange vs. communal norms in friendship. Journal of Experimental Social Psychology, 53, 7993. https://doi.org/10.1016/j.jesp.2014.02.006.

Mills, J. R., \& Clark, M. S. (1982). Communal and exchange relationships. In L. Wheeler (Ed.), Review of personality and social psychology (pp. 121-144). Beverly Hills: Sage.

Molm, L. D., Whitham, M. M., \& Melamed, D. (2012). Forms of exchange and integrative bonds: Effects of history and embeddedness. American Sociological Review, 77, 144 165. https://doi.org/10.1177/00031224111434610.

Morgan, B., \& Gulliford, L. (2018). Assessing influence on gratitude experience: Age-related differences in how gratitude is understood and experienced. In J. R. H. Tudge \& L. B. L. Freitas (Eds.), Developing gratitude in children and adolescents (pp. 65-88). Cambridge: Cambridge University Press.

Nelson, J. A., Freitas, L. B. L., O’Brien, M., Calkins, S. D., Leerkes, E. M., \& Marcovitch, S. (2013). Preschool-aged children's understanding of gratitude: Relations with emotion and mental state knowledge. British Journal of Developmental Psychology, 31, 4256. https://doi.org/10.1111/j.2044-835X.2012.02077.x.

O’Brien, L., Liang, Y., Merçon-Vargas, E. A., Price, U. S., \& Leon, E. D. (2018). Relations between parents' and children's gratitude. In J. R. H. Tudge \& L. B. L. Freitas (Eds.), Developing gratitude in children and adolescents (pp. 177-198). Cambridge: Cambridge University Press. 
Payir, A., Liang, Y., Mendonça, S. A., Mokrova, I. L., Palhares, F., \& Zeytinoglu, S. (2018). Cross-cultural variations in the development of gratitude. In J. R. H. Tudge \& L. B. L. Freitas (Eds.), Developing gratitude in children and adolescents (pp. 111-134). Cambridge: Cambridge University Press.

Piaget, J. (1981). Intelligence and affectivity: Their relationship during child development. Palo Alto: Annual Reviews (Original work published in 1954).

Piaget, J. (1995). Sociological studies. New York: Routledge (Original work published in 1965).

Ramsey, M. A., Gentzler, A. L., \& Vizy, B. (2018). Children's and parents' understanding of gratitude. In J. R. H. Tudge \& L. B. L. Freitas (Eds.), Developing gratitude in children and adolescents (pp. 220-239). Cambridge: Cambridge University Press.

Roberts, R. C. (2004). The blessings of gratitude: A conceptual analysis. In R. A. Emmons \& M. E. McCullough (Eds.), The psychology of gratitude (pp. 58-78). New York: Oxford University Press.

Rothenberg, W. A., Hussong, A. M., Langley, H. A., Egerton, G. A., Halberstadt, A. G., Coffman, J. L., Mokrova, I., \& Costanzo, P. R. (2017). Grateful parents raising grateful children: Niche selection and socialization of child gratitude. Applied Developmental Science, 21, 106-120. https://doi.org/10.1080/10888691.2016.1175945.

Smith, A. (2000). The theory of moral sentiments. New York: Prometheus (First published in 1759).

Tudge, J. R. H., \& Freitas, L. B. L. (2018). Developing gratitude: An introduction). In J. R. H. Tudge \& L. B. L. Freitas (Eds.), Developing gratitude in children and adolescents (pp. 122). Cambridge: Cambridge University Press.

Tudge, J. R. H., Freitas, L. B. L., \& O’Brien, L. T. (2015). The virtue of gratitude: A developmental and cultural approach. Human Development, 58, 281300. https://doi.org/10.1037//0022-3514.82.1.112.

Vaish, A., Hepach, R., \& Tomasello, M. (2018). The specificity of reciprocity: Young children reciprocate more generously to those who intentionally benefit them. Journal of Experimental Child Psychology, 167, 336353. https://doi.org/10.1016/j.jecp.2017.11.005.

Visser, M. (2009). The gift of thanks: The roots and rituals of gratitude. Boston: HoughtonMiflin.

Wang, D., Wang, Y. C., \& Tudge, J. R. H. (2015). Expressions of gratitude in children and adolescents: Insights from China and the United States. Journal of Cross-Cultural Psychology, 46, 1039-1058. https://doi.org/10.1177/0022022115594140.

Watkins, P. C., Woodward, K., Stone, T., \& Kolts, R. L. (2003). Gratitude and happiness: Development of a measure of gratitude, and relationships with subjective wellbeing. Social Behavior and Personality, 31, 431452. https://doi.org/10.2224/sbp.2003.31.5.431. 
Watkins, P. C., Grimm, D. L., \& Kolts, R. (2004). Counting your blessings: Positive memories among grateful persons. Current Psychology, 23(1), 52-67.

Wood, A. M., Froh, J. J., \& Geraghty, A. W. A. (2010). Gratitude and well-being: A review and theoretical integration. Clinical Psychology Review, 30(7), 890905. https://doi.org/10.1016/j.cpr.2010.03.005. 